\title{
Studi Komparatif Penerapan Model Pembelajaran Daring Media Whatsapp Group dengan Media Blogspot terhadap Hasil Belajar IPS
}

\author{
Ahmad Amarudin $₫$, Universitas PGRI Madiun \\ Muhammad Hanif, Universitas PGRIMadiun \\ Sudarmiani, Universitas PGRI Madiun \\ $\triangle$ zekkye.amar@gmail.com
}

\begin{abstract}
Abstrak. Penelitian ini bertujuan untuk mengetahui perbedaan pengaruh penerapan pembelajaran daring menggunakan media whatsapp dan blogspot terhadap hasil belajar IPS kelas IV SDN 1 Somoroto. Metode penelitian yang digunakan adalah true-eksperimen. Desain penelitian ini menggunakan posttest only control design. Sampel penelitian ini adalah siswa kelas IV SDN 1 Somoroto yang berjumlah 54 siswa. Teknik analisis data yang digunakan adalah analisis uji beda atau uji-t (t-test). Hasil penelitian ini menunjukkan hasil hitung statistik deskriptif menunjukkan di kelas PJJ menggunakan media whatsapp memperoleh nilai rata-rata sebesar 78 dan nilai standart deviasi sebesar 8,104 artinya rentangan sebasaran rata-rata nilai di kelas ini adalah antara 18 poin. Hasil hitung statistik deskriptif menunjukkan di kelas PJJ menggunakan media blogspot memperoleh nilai rata-rata sebesar 72 dan nilai standart deviasi sebesar 10,483 artinya rentangan sebasaran rata-rata nilai di kelas ini sangat besar yaitu antara 1-10 poin. Terdapat perbedaan pengaruh yang signifikan penerapan pembelajaran daring menggunakan media whatsapp dan blogspot terhadap hasil belajar IPS kelas IV SDN 1 Somoroto. Hal ini dibuktikan dengan nilai thitung dengan ttabel adalah 3,658>2,056.
\end{abstract}

Kata Kunci: Whatsapp Group; Blogspot; Hasil Belajar IPS

Abstract. This study aims to determine the difference in the effect of implementing online learning using whatsapp and blogspot media on social studies learning outcomes for class IV SDN 1 Somoroto. The research method used is true-experiment. The design of this study used a posttest only control design. The sample of this study was the fourth grade students of SDN 1 Somoroto, totaling 54 students. The data analysis technique used is the analysis of the difference test or t-test (t-test). The results of this study show that the results of descriptive statistics show that the PJJ class using WhatsApp media gets an average value of 78 and a standard deviation value of 8.104 , meaning that the average range of values in this class is between 1-8 points. The results of descriptive statistical calculations show that the PJJ class using blogspot media gets an average value of 72 and a standard deviation value of 10,483 meaning that the range of average values in this class is very large, which is between 1-10 points. There is a significant difference in the effect of the application of online learning using whatsapp and blogspot media on social studies learning outcomes for class IV SDN 1 Somoroto. This is evidenced by the value of tcount with ttable is $3.658>2.056$.

Keywords: Whatsapp Group; Blogspot; IPS Learning Outcomes

Citation: Amarudin, A., Hanif, M., \& Sudarmiani, S. (2022). Studi Komparatif Penerapan Model Pembelajaran Daring Media Whatsapp Group dengan Media Blogspot terhadap Hasil Belajar IPS. Wewarah: Jurnal Pendidikan Multidisipliner, 1(1), 61 - 66.

\section{(cc) $\mathrm{EY}$}

Published by Program Pascasarjana Universitas PGRI Madiun. This work is licensed under the Creative Commons AttributionNonCommercial-ShareAlike 4.0 International License. 


\section{PENDAHULUAN}

Pendidikan di Indonesia mengalami perubahan pendekatan dan cara belajar siswa. Kondisi masa pandemi melahirkan kebijakan baru melalui SKB 4 Menteri yang mengintruksikan kepada seluruh pelaksana pendidikan di Indonesia untuk melaksanakan pembelajaran jarak jauh. Kebijakan tersebut juga berdampak pada bidang pendidikan, salah satunya tertuang pada Surat Edaran Mendikbud Nomor 4 Tahun 2020 Tentang Pelaksanaan Kebijakan Pendidikan Dalam Masa Darurat Penyebaran COVID, dalam Surat Edaran tersebut dijelaskan bahwa proses belajar dilaksanakan di rumah melalui pembelajaran daring/jarak jauh dilaksanakan untuk memberikan pengalaman belajar yang bermakna bagi siswa.

Pembelajaran jarak jauh terbagi menjadi dua yaitu pembelajaran daring (dalam jaringan) dan luring (luar jaringan). Pembelajaran daring dilakukan dengan cara melibatkan semua komunikasi pembelajaran dengan menggunakan jaringan internet, seperti menggunakan zoom metting, google meet, aplikasi media sosial whatsapp, dan aplikasi dalam jaringan lainnya. Sedangkan pembelajaran luring adalah pembelajaran yang komunikasinya menggunakan media elektronik yang tidak tersambung dengan internet, seperti menggunakan acara televisi, radio, dan lain-lain. Sumiati dan Asra (2010: 3) pembelajaran pada hakekatnya merupakan suatu proses yang kompleks (rumit), namun dengan maksud yang sama yaitu memberi pengalaman belajar kepada siswa sesuai dengan tujuan. Oleh sebab itu, peran guru dalam pembelajaran ialah memberikan rangsangan atau stimulan agar siswa mau belajar atau mempelajari materi pelajaran tertentu untuk mencapai tujuan pembelajaran tersebut. Sedangkan menurut Sanjaya (2012: 198) berpendapat pembelajaran adalah proses kerjasama dan komunikasi antara siswa dengan guru atau dengan lingkungannnya untuk mencapai tujuan tertentu. Dalam kegiatan pembelajaran terjadi interaksi dengan berbagai bahan dan sumber belajar untuk mencapai tujuan tertentu. Bahan dan sumber belajar tersebu termasuk peranan guru di dalamnya, serta berbagai media pembelajaran lainnya.

Proses belajar yang dilaksanakan siswa dapat terwujud melali pembelajaran, dan pembelajaran dapat berjalan melalui adanya model pembelajaran sebagai acuan pelaksanaannya. Secara empiris model pembelajaran merupakan bentuk dari kerangka pembelajaran yang hendak dilaksanakan yang terdiri langkah mencapai tujuan belajar. Dorin, et all (dalam Yulaelawati, 2007: 37) menjelaskan bahwa model merupakan gambaran mental yang membantu kita untuk menjelaskan sesuatu dengan lebih jelas terhadap sesuatu yang tidak dapat dilihat atau tidak dialami secara langsung. Merujuk pengertian model tersebut, maka model pembelajaran secara dasar merupakan gambaran bentuk atau pola yang akan digunakan untuk melakukan kegiatan pembelajaran akan mudah dipahami oleh siswa. Menurut Julianto (2011: 79) model pembelajaran merupakan bentuk pembelajaran yang tergambar dari awal sampai akhir pembelajaran sintak pembelajaran yang disajikan secara khas oleh guru dalam pembelajaran di kelas. Istilah model pembelajaran meliputi pendekatan suatu model pembelajaran yang luas dan menyeluruh. Model pembelajaran dapat diklasifikasikan berdasarkan tujuan pembelajarannya, sintaks (pola urutannya dan sifat lingkungan belajarnya. Sintaks atau urutan model pembelajarn dari suatu model pembelajaran adalah pola yang menggambarkan urutan alur tahap-tahap keseluruhan yang pada umumnya disertai dengan serangkaian kegiatan pembelajaran. Sintaks dari setiap model pembelajarn memiliki komponen-komponen yang sama.

Penerapan pembelajaran jarak jauh memiliki tujuan untuk menciptakan suasana pembelajaran yang tetap efektif meskipun dilakukan tanpa tatap muka serta dapat melibatkan media berbasis IT yang lebih modern sehingga pembelajaran menjadi lebih baik. Seperti yang disebutkan Chaeruman (2017: 6) bahwa ide dasar SPADA Indonesia adalah penerapan sistem pendidikan jarak jauh/terbuka, e-learning dan massive open daring course (MOOCs) untuk meningkatkan akses terhadap pendidikan tinggi yang bermutu melalui penerapan teknologi informasi dan komunikasi yang tepat sebagai wahana alih kredit, program pendidikan (degree program), pengembangan profesi berkelanjutan dan belajar sepanjang hayat bagi seluruh masyarakat Indonesia.

Pembelajaran daring merupakan pembelajaran yang memanfaatkan teknologi multimedia, video, kelas virtual, teks online animasi, pesan suara, email, telepon konferensi, dan video steraming online Pembelajaran dapat dilakukan secara masif dengan jumlah peserta yang tidak terbatas, bisa dilakukan secara gratis maupun berbayar (Bilfaqih \& Qomarudin, 2015). Isman dalam Dewi Wahyu A.F. (2020: 56) pembelajaran daring merupakan pemanfaatan jaringan internet dalam proses pembelajaran. Dengan pembelajaran daring siswa memiliki keleluasaan waktu belajar, dapat belajar kapanpun dan dimanapun. Siswa dapat berinteraksi dengan guru menggunakan beberapa aplikasi seperti classroom, video converence, telepon atau live chat, zoom maupun melalui Whatsapp group. Pembelajaran ini merupakan inovasi pendidikan untuk menjawab tantangan akan ketersediaan sumber belajar yang variatif.

Pembelajaran jarak jauh salah satunya dapat dilakukan dengan menggunakan aplikasi Whatsapp Group dan menggunakan blogspot. Berdasarkan studi empirik yang dilakukann oleh peneliti dari hasil penelitian Afnibar dan Fajhriani (2020) menyimpulkan media whatsApp memudahkan mereka dalam berkomunikasi dan menunjang kegiatan belajar dibandingkan media online lainnya. Sedangkan menurut Trisnani (2017: 42) Media sosial merupakan salah satu media dimana para penggunanya dapat mencari informasi, saling berkomunikasi dan menjalin pertemanan secara online. Seperti diketahui ragam media social, yakni adalah facebook, twitter, line, bbm, Whatsapp, instagram, path, linkedin, snapchat dan beberapa media sosial yang lain. Penggunaan Whatsapp 
sebagai media online dalam dunia pendidikan semakin tahun semakin meningkat seiring dengan meningkatnya kebutuhan dosen dan mahasiswa untuk saling berinteraksi dengan seseorang atau sekelompok orang yang berjarak secara fisik.Hal ini menunjukkan jika penggunaan media whatsapp ecara baik untuk berinteraksi berkelanjutan membahas materi pelajaran akan membuat siswa semakin mudah memahami materi. Blog sebagai salah satu layanan aplikasi dari internet dapat dimanfaatkan oleh guru dan siswa sebagai sumber belajar yang tidak terbatas. Guru dapat mengunggah semua informasi yang berkaitan dengan materi pembelajaran yang diajarkan dengan menambahkan multimedia (gambar, animasi, efek suara dan video) agar menarik dan lebih mudah dipelajari (wikipedia.com, 2019).

Pembelajaran daring menggunakan media blog juga sudah sering dilakukan oleh kalangan pelaku pendidikan, salah satunya sering diterapkan pada perguruan tinggi. Blog menurut pendapat Ananda (2013 : 11) merupakan suatu aplikasi, software atau perangkat lunak berbasis web yang dibuat seseorang (blogger atau pengguna blog) secara sengaja dengan tujuan dan alasan tertentu yang dirancang sedemikian rupa dalam bentuk teks, gambar dan video yang dapat digunakan untuk menyajikan materi pembelajaran secara online. Blogger merupakan layanan yang disediakan secara gratis oleh google bagi para pengguna internet yang ingin membagi karya-karyanya melalui media berupa web atau blog. Blogger memberikan kemudahan bagi penggunanya karena dapat membuat situs blog tanpa harus bersusah payah. Blogger telah menyediakan fasilitas blog yang lengkap. Di antaranya dapat membuat posting tulisan dengan mudah, melakukan pengaturan blog, melakukan modifikasi tampilan blog, bahkan membaginya dengan user yang lain melalui media sosial hanya dengan sekali klik. Secara teori penggunaan media blog memiliki banyak kelebihan seperti yang dijelaskan oleh Lukmana $(2013: 17)$ manfaat blogspot untuk guru adalah (1) Mempermudah komunikasi guru. Guru dapat membuat blog jika ingin lebih mudah berkomunikasi dengan siswa, wali murid, atau guru yang lain. Konten yang ada di blog bisa sekedar posting pekerjaan rumah atau materi pelajaran yang lebih kompleks. Di blog semua bisa dilakukan dengan sederhana karena blog mudah ditemukan; (2) Mendukung tumbuhnya komunikasi. Ketika guru menuliskan sesuatu di blog maka akan cenderung ditanggapi oleh siswa atau guru lain. Misalnya guru menuliskan sesuatu, kemudian guru ingin siswa menjawab maka siswa tinggal mengisikannya dikolom komentar dan dialogpun terjadi.

Sedangkan menurut Panjaitan (2013 : 6) Manfaat blog bagi guru adalah (1) Tempat penyimpanan online bagi guru; (2) Menjadi media pembelajaran online; (3) membuktikan profesional guru; dan (4) Menjalin komunikasi online. Berdasarkan pendapat kebermanfaatan dari blogspot dalam pembelajaran menurut para ahli di atas, maka dapat disimpulkan kelebihan pembelajaran daring menggunakan blogspot adalah: (1) media blogspot dalam pembelajaran tidak mengenal waktu atau dapat diakses penuh 24 jam; (2) hemat, karena blogspot ada yang gratis; (3) melalui blogspot dapat terjalin interaksi yang positif; (4) mudah dan cepat serta sederhana pembuatannya, karena langkahnya mudah. Secara empirik penggunaan media blog sebagai sarana untuk pembelajaran siswa telah dilakukan oleh Sartono (2016) yang menyimpulkan hasil penelitiannya bahwa media blog efektif digunakan sebagai media pembelajaran alternatif di sekolah karena dapat meningkatkan prestasi dan motivasi belajar siswa.

Berdasarkan uraian di atas pembelajaran daring menggunakan media whatsapp dan blogspot yang sedang berlangsung selama pandemi Covid-19 di SDN 1 Somoroto yang sebelumnya belum pernah diadakan penelitian, sangat menarik untuk di teliti guna mengetahui perbedaan pengaruh terhadap hasil belajar IPS kelas IV SDN 1 Somoroto.

\section{METODE PENELITIAN}

Penelitian ini menggunakan pendekatan kuantitatif true-eksperimen. Sugiyono (2015: 107) metode eksperimen dapat diartikan sebagai metode penelitian yang digunakan untuk mencaru pengaruh perlakuan tertentu terhadap yang lain dalam kondisi yang dikendalikan. Metode eksperimen yang digunakan pada penelitian ini adalah posttest only control design.

Populasi dalam penelitian ini adalah siswa kelas IV SDN 1 Somoroto yang berjumlah 54 siswa. Teknik pengambilan sampel pada penelitian ini adalah teknik pengambilan sampel jenuh. Menurut Sugiyono (2015:126) sampling jenuh adalah teknik penentuan sampel bila semua anggota popilasi digunakan sebagai sampel. Sehingga jumlah sampel yang digunakan adalah sebanyak 54 siswa yang terbagi menjadi dua kelas, yakni kelas (model pembelajaran daring whatsapp) di kelas IVA dan kelas (model pembelajaran daring blogspot) di kelas IVB. Data primer dalam penelitian ini adalah hasil belajar siswa, maka teknik pengambilan datanya menggunakan lembar tes untuk hasil belajar IPS. Instrumen yang digunakan peneliti untuk mengumpulkan data penelitian ini adalah lembar tes tertulis dengan bentuk soal pilihan ganda (multiple choice). Isi soal berasal dari materi IPS pada Tema 1 Subtema 1 Kelas IV sekolah dasar.

Teknik analsis data pada penelitian ini menggunakan analisis uji beda menggunakan uji-t (t-test). Sebelum dilakukan uji t terlebih dahulu melalui uji prasyarat uji normalitas dan homogenitas data. Uji normalitas dalam penelitian ini dilakukan dengan menggunakan rumus chi-kuadrat. Uji homogenitas data pada penelitian ini menggunakan rumus Harley. Selanjutnya dilakukan uji hipotesis, pengujian hipotesis menggunakan uji-t. 
Penarikan kesimpulan uji-t jika $t_{\text {hitung }}>t_{\text {tabel }}$, artinya hipotesis diterima; dan jika $t_{\text {hitung }}<t_{\text {tabel }}$, artinya hipotesis pada penelitian ini ditolak.

\section{HASIL DAN PEMBAHASAN}

\section{Hasil}

SDN 1 Somoroto adalah merupakan SD senter di kecamatan kauman kabupaten ponorogo yang pada saat ini memiliki jumlah siswa 394 siswa terdiri atas 14 rombel, dengan rincian kelas I sebanyak 3 rombel, kelas II dua rombel kelas III dua rombel Kelas IV dua rombel kelas V dua rombel dan kelas VI tiga rombel.

Hasil penelitian pada siswa Kelas IV yang menggunakan kelas pembelajaran jarak jauh menggunakan whatsapp diperoleh hasil analisis statistik dari data hasil belajar siswa, yaitu mean (rata-rata) nilai kelas PJJ melalui whatsapp adalah 78. Median (nilai tengah) adalah 80. Mode (nilai yang dominan) adalah 75. Serta Standar deviasi adalah 8,104. Hasil hitung mean atau rata-rata di kelas PJJ melalui media Whatsapp diperoleh 78, sehingga sejumlah 14 siswa atau 52\% dari keseluruhan siswa memperoleh hasil belajar di atas rata-rata, sedangkan sisaanya sejumlah 13 siswa atau $48 \%$ memperoleh hasil belajar di bawah nilai rata-rata kelas.

Sedangkan pada kelas IV yang menggunakan kelas kelas PJJ melalui blogspot diperoleh hasil analisis statistik deskriptif yaitu mean (rata-rata) nilai kelas PJJ melalui blogspot adalah 72. Median (nilai tengah) adalah 70. Mode (nilai yang dominan) adalah 70. Serta Standar deviasi adalah 10,483. Hasil hitung mean atau rata-rata di kelas PJJ melalui media blogspot diperoleh 72, sehingga sejumlah 11 siswa atau $41 \%$ dari keseluruhan siswa memperoleh hasil belajar di atas rata-rata, sedangkan sisaanya sejumlah 16 siswa atau 59\% memperoleh hasil belajar di bawah nilai rata-rata kelas.

Berdasarkan hasil analisis statistik deskriptif di kedua kelas di atas menunjukkan terdapat perbedaan pada setiap hasil analisis. Nilai mean (rata-rata) di kelas kelas PJJ melalui whatsapp adalah 78. Sedangkan nilai mean (rata-rata) pada kelas PJJ melalui blogspot ialah sejumlah 72. Dengan demikian secara nilai rata-rata hasil belajar siswa, kelas PJJ melalui whatsapp lebih unggul dibandingkan dengan kelas PJJ melalui media blogspot.

Hasil analisis uji prasyarat (uji normalitas data) diperoleh hasil hitung Chi-Square pada data kelas PJJ melalui whatsapp adalah 8,519. Nilai tersebut kemudian dibandingkan dengan nilai Chi-Square Tabel dengan df 6 dengan taraf signifikansi 5\% yaitu 12,592. Hasil perbandingannya adalah nilai hitung Chi-Square $=8,519<12,592$ yang artinya data hasil belajar kelas PJJ melalui whatsapp berdistribusi normal. Sedangkan hasil hitung Chi-Square pada data kelas PJJ melalui blogspot adalah 5,296. Nilai tersebut kemudian dibandingkan dengan nilai Chi-Square Tabel dengan df 7 dengan taraf signifikansi 5\% yaitu 14,067. Hasil perbandingannya adalah nilai hitung ChiSquare = 5,296 < 14,067 yang artinya data hasil belajar kelas PJJ melalui blogspot berdistribusi normal.

Hasil analisis uji prasyarat (uji homogenitas data) diperoleh diperoleh nilai hitung Harley dilihat dari kolom based on mean yaitu 1,553. Nilai tersebut kemudian dibandingan dengan nilai tabel F dengan df $1=1$ dan df $2=$ 52 yaitu 4,03. Hasil perbandingan nilai hitung Harley (based on mean) dengan nilai tabel F adalah 1,553<4,03 artinya data nilai hasil belajar kognitif kelas PJJ melalui whatsapp dan Blogspot bersifat homogen.

Hasil analisis data melalui uji beda (uji-t) diperoleh nilai hitung uji-T yaitu 3,658. Nilai tersebut kemudian dibandingkan dengan nilai tabel $\mathrm{T}$ dengan df 26 yaitu 2,056. Adapun hasil perbandingan nilai thitung dengan ttabel adalah 3,658 > 2,056 yang artinya hipotesis diterima. Dengan demikian hipotesis penelitian ini terbukti yakni penerapan pembelajaran daring menggunakan media whatsapp group lebih baik dibandingkan dengan menggunakan blogspot terhadap hasil belajar IPS kelas IV SDN 1 Somoroto.

\section{Pembahasan}

Hasil pengujian hipotesis diperoleh hasil bahwa nilai thitung $=3,658$ dan nilai t tabel dengan df 26 pada taraf signifikan 5\% ialah 2,056. Hasil perbandingannya diperoleh thitung $=3,658>2,056=$ ttabel. Artinya Ho ditolak dan Ha diterima, sehingga ada perbedaan yang signifikan penerapan pembelajaran daring menggunakan media whatsapp dan blogspot terhadap hasil belajar IPS kelas IV SDN 1 Somoroto. Memperhatikan nilai rata-rata hasil belajar IPS siswa yang menggunakan pembelajaran melalui Whatsapp sebesar 78,1481 dan nilai rata-rata hasil belajar siswa dengan menggunakan pembelajaran blogspot sebesar 71,8519 ini berarti hasil belajar TEMA 1 muatan IPS dengan menggunakan pembelajaran melalui Whatsapp lebih baik bila dibandingkan dengan menggunakan pembelajaran blogspot.

Pembelajaran menggunakan Whatsapp merupakan pembelajaran jarak jauh yang komunikasi penyampaian materinya menggunakan media aplikasi komunikasi whatsapp. Sehingga meskipun pembelajaran dilakukan secara jarak jauh dapat terjalin interaksi dengan baik dan mudah antara guru dengan siswa dan orangtua selaku pendamping siswa belajar dari rumah. Komunikasi yang baik ini akan membuat dampak teratasinya masalahmasalah yang siswa hadapi dalam memahami materi dan mengerjakan tugas.

Menurut Aliran kognitif mendefinisikan pembelajaran sebagai cara guru memberikan kesempatan kepada siswa untuk berpikir agar mengenal dan memahami sesuatu yang sedang dipelajari. Melalui pembelajaran akan 
tercipta interaksi antara guru dengan siswa yang tujuannya untuk membelajarkan siswa, sehingga tujuan pembelajaran dapat tercapai (Darsono dalam Hamdani, 2011: 23).

Sejalan dengan pendapat dan teori di atas pembelajaran dengan menggunakan whatsapps akan mempermudah interaksi secara daring antara guru dengan siswa atau dengan orangtua yang mendampingi anak belajar di rumah. Artinya ketika siswa atau orangtua menemui kesulitan-kesulitan belajar dapat bertanya dengan mudah dan cepat melalui pesan whatsapp, karena siswa dan orangtua sudah terbiasa dengan penggunaanWhatsapp setiap hari yang didukung kepemilikan HP yang sudah suport, sehingga tujuan pembelajaran dapat tercapai secara efektif dan efisien karena pesan whatsapp tidak memerlukan biaya yang begitu banyak.

Hal ini berbeda dengan pembelajaran menggunakan blogspot dikarenakan melalui blogspot meskipun materi dapat dibuat menarik namun tidak semua orangtua dapat mengakses blogspot, dikarenakan kemampuan IT dan HP yang tidak suport. Selain itu pada blogspot kelancaran komunikasi terbatas pada papan komentar di bawah jendela blogspot sehingga membuat kecepatan respon dari guru lambat karena tidak ada notifikasi pemberitahuan adanya pesan di blogspot. Pada penerapan pembelajaran menggunakan blogspot ini hanya beberapa siswa yang mampu memahami materi dan masih banyak siswa yang belum tuntas yang dapat dilihat dari nilai rata-rata kelas PJJ melalui blogspot sebesar 71,859.

Dengan demikian yang membedakan pengaruh pembelajaran menggunakan whatsapp dengan blogspot adalah terletak pada sisi kemudahan penggunaan dan sisi kelancaran komunikasi antara guru dan siswa atau orangtua. Sehingga dengan kelancaran komunikasi pembelajaran yang menggunakan whatsapp berdampak banyaknya masalah-masalah kesulitan belajar siswa yang dapat diatasi oleh guru maka dapat berdampak pada pencapaian hasil belajar siswa yang maksimal. Hal ini juga didukung dengan hasil penelitian Penelitian yang dilakukan oleh Shodiq dan Zainiyati (2020) menyimpulkan bahwa pemanfaatan whatshapp sebagai media pembelajaran ditengan pandemi covid 19 seperti saat ini sangatlah tepat, mengingat aplikasi ini sangat sederhana bila dibandingkan dengan aplikasi online lainnya, mudah dalam pengoperasiannya dan tentunya memiliki fiturfitur yang banyak. Selain sebagai media pembelajaran pemanfaatan whatsapp dalam aktivitas edukasi bertujuan sebagai sarana edukasi, sebagai sarana evaluasi, sebagai sarana penyambung informasi, dan sebagai sarana layanan konsultasi dan menjalin silaturahim. Temuan ini menunjukkan bahwa dengan pembelajaran daring menggunakan whatsapp seorang guru dapat bekerja sama dnegan orangtua dalam mendidik anak atau siswa sehingga terjalin komunikasi nyang interaktif serta aktif dan dapat mempermudah proses belajar siswa.

\section{SIMPULAN}

Berdasarkan hasil penelitian di atas maka disimpulkan bahwa frekuensi siswa yang memperoleh nilai di atas ratarata sejumlah 14 siswa atau 52\% dan di bawah rata-rata sejumlah 13 siswa atau 48\%, yang artinya banyak siswa yang mampu memahami materi dengan baik di kelas PJJ dengan media whatsapp. Sedangkan kelas PJJ menggunakan media blogspot diperoleh frekuensi siswa yang memperoleh nilai di atas rata-rata sejumlah 11 siswa atau $42 \%$ dan di bawah rata-rata sejumlah 16 siswa atau 58\%, yang artinya banyak siswa yang belum mampu memahami materi dengan baik di kelas PJJ dengan media blogspot. Selain itu terdapat perbedaan pengaruh yang signifikan penerapan pembelajaran daring menggunakan media whatsapp dan blogspot terhadap hasil belajar IPS kelas IV SDN 1 Somoroto. Hal ini dibuktikan dengan nilai thitung dengan ttabel adalah 3,658>2,056. Perbedaan tersebut dapat dijelaskan bahwa kelas dengan pembelajaran daring menggunakan media whatapps group lebih efektif dan pencapaian hasil belajar siswa lebih baik dibandingkan dengan pembelajaran daring menggunakan media blogspot.

\section{DAFTAR PUSTAKA}

Afnibar dan Fajhriani. 2020. Pemanfaatan Whatsapp Sebagai Media Komunikasi Antara Dosen Dan Mahasiswa Dalam Menunjang Kegiatan Belajar. Jurnal Komunikasi dan Penyiaran Islam Volume 11 Nomor 1, Januari-Juni 2020.

Anugrahana Andri. 2020. Hambatan, Solusi dan Harapan: Pembelajaran Daring Selama Masa Pandemi Covid19 Oleh Guru Sekolah Dasar. Universitas Sanata Dharma: Jurnal Pendidikan dan Kebudayaan, Vol. 10 No. 3, September 2020: 282-289.

Aunurrahman.2010. Belajar dan Pembelajaran. Bandung: Alfabeta.

Bilfaqih, Y \& Qomarudin, M. N. 2015. Esensi Pengembangan Pembalajaran Daring. 131.

Dewi Wahyu A.F. 2020. Dampak Covid-19 Terhadap Implementasi Pembelajaran Daring Di Sekolah Dasar. Universitas Pahlawan: Jurnal Ilmu Pendidikan Volume 2 Nomor 1 April 2020.

Julianto. 2011. Model Pembelajaran IPA. Surabaya: Unesa University Press.

Lukmana. 2013. Guru GO BLOG. Yogyakarta : CV Andi Offset.

Mulyono Tj. 1980. Pengertian dan Karakteristik Ilmu Pengetahuan Sosial. Jakarta: Depdikbud

Panjaitan. 2013. Mengelola Blog Sebagai Media Pembelajaran Online. Yogyakarta : Leutikaprio

Sanjaya. 2012. Media Komunikasi Pembelajaran. Jakarta: Kencana Prenada Media Group. 
Sari, Asran, dan Tirtowati. 2015. Pengaruh Model Project Based Learning Terhadap Hasil Belajar Siswa Pada Pembelajaran IPS Di Kelas V. Jurnal UNTAN Prodi Pendidikan Guru Sekolah Dasar.

Sartonoo. 2016. Pemanfaatan Blog Sebagai Media Pembelajaran Alternatif di Sekolah. Jurnal ransformatika, Volume 12, Nomer 1, Maret 2016

Sarwono, Santosa, dan Soegiyanto. 2016. Pengaruh Model Pembelajaran Project Based Learning Terhadap Pengetahuan Bencana Alam Di Indonesia Dan Perilaku Cinta Lingkungan Hidup Siswa Kelas X SMA N 2 Surakarta Tahun 2015. Universitas Sebelas Maret: Jurnal GeoEcool. 2, No. 2 (Juli 2016) Hal. 184-197.

Setyosari Punaji. 2012. Metode Penelitian Pendidikan dan Pengembangan. Jakarta: Kencana Prenada Media Group.

Sugiyono. 2015. Metode Penelitian Pendidikan (PendekatanKuantitatif, Kualitatif, dan $R \& D$ ). Bandung: Alfabeta.

Sugiyono. 2015. Statistikauntuk Penelitian. Bandung: Alfabeta.

Sumiati dan Asra, 2010. Metode Pembelajaran. Bandung: Wacana Prima.

Susanto, A. 2013. Teori Belajar dan Pembelajaran di SekolahDasar. Jakarta: Kencana Prenada Media Group.

Trianto. 2011. Mendesain Model Pembelajaran Inovatif-Progresif. Jakarta: Kencana.

Yulaelawati, 2007.Kurikulum dan Pembelajaran Filosofi, Teori, dan Aplikasi. Jakarta: Pakar Raya. 